\title{
ANÁLISE PRELIMINAR DA QUALIDADE DA ÁGUA DE RIOS EM CURITIBANOS, SC
}

\section{Gabrielle França}

Ribeiro' ${ }^{1}$ Graduanda em

Medicina Veterinária pela UFSC

Universidade Federal de Santa

Catarina, no Centro de Ciências

Rurais, Curitibanos/SC, E-mail:

gabriellefrancaribeiro@gmail.com

\section{Júlia Elizabeth}

Proença $^{2}$, Graduanda de

Engenharia Florestal na UFSC,

Campus de Curitibanos.

Trabalha como Agente de

Pesquisa e Mapeamento no

Instituto Brasileiro de Geografia e

Estatística (IBGE) E-mail:

juh2206@gmial.com

\section{Natalia Maria}

\section{Martinazzo Angelo ${ }^{3}$}

Graduanda do curso de

Engenharia Florestal UFSC Campus Curitibanos. E-mail: nmmartinazzo@gmail.com

\section{Sonia Purin da Cruz}

Professora de Microbiologia UFSC. Ph.D. em Ciências do Solo e Vegetal (Área de Concentração: Microbiologia Ambiental e Aplicada) pela West Virginia University, Estados Unidos. Trabalhou no INVAM (International Culture Collection of Vesicular Arbuscular Mychorrhizal Fungi) sob orientação do Ph.D. Joseph B. Morton. O programa foi integralmente financiado pela CAPES/Fulbright. E-mail: s.purin@ufsc.br

\author{
PRELIMINARY ANALYSIS OF WATER QUALITY FROM \\ RIVERS IN CURITIBANOS, SC
}

\section{RESUMO}

A água é um elemento vital e tem efeitos diretos em aspectos ecológicos e na saúde pública. Todavia, no meio rural, grande parte das comunidades não são amparadas pelas redes de abastecimento, fazendo com que a obtenção deste recurso para fins de consumo, irrigação e demais usos ocorra através de nascentes e rios, sem o devido saneamento. A contaminação dos corpos d'água por coliformes fecais representa uma origem comum e um veículo de patógenos, além de uma fonte de elementos de resistência a antibióticos em bactérias oriundas de variados nichos. Assim, neste trabalho avaliou-se a condição microbiológica da água e o perfil de resistência a antibióticos em bactérias isoladas de amostras procedentes Rio Pessegueirinho e Rio Marombas, localizados no município de Curitibanos, SC, na primavera de 2020 e verão de 2021. As duas maiores médias de concentração de coliformes fecais foram observadas na coleta do verão, correspondendo a 1.100 NMP $100 \mathrm{~mL}-1$. Os níveis mais altos de resistência aos antibióticos testados também foram equivalentes às amostras coletadas no verão, em que 35\% dos isolados demonstrou resistência frente à tetraciclina, e 21,66\%, à ampicilina. Dados os resultados, evidencia-se um alto grau de contaminação fecal nestas águas, o que representa uma ameaça aos indivíduos que fazem uso das mesmas, e revela a necessidade de realizar o monitoramento periódico da qualidade hídrica.

PALAVRAS-CHAVE: Água. Antibióticos. Coliformes.

\section{ABSTRACT}

Water is a vital element and has direct effects on ecological aspects and public health. However, in rural areas, a large part of communities is not supported by supply networks; hence this resource is acquired for consumption, irrigation and other uses through springs and rivers, without proper sanitation. The contamination of water bodies by fecal coliforms represents a common origin and a vehicle for pathogens, as well as a source of antibiotic resistance elements in bacteria from various niches. Thus, in this work, the microbiological condition of the water and antibiotic resistance profile in bacteria isolated from samples from Rio Pessegueirinho and Rio Marombas, located in the municipality of Curitibanos, SC, were evaluated at spring 2020 and summer 2021. The two highest averages of fecal coliforms concentration were observed at summer, corresponding to $1,100 \mathrm{MPN} 100 \mathrm{~mL}-1$. Highest levels antibiotic resistance were 
also detected at summer, when $35 \%$ of the isolates demonstrated resistance to tetracycline, and $21.66 \%$, to ampicillin. Given the results, there is a high degree of faecal contamination in these waters, what represents a threat to the individuals who use them, and reveals the need to carry out periodic monitoring of water quality.

KEYWORDS: Water. Antibiotics. Coliforms.

\section{INTRODUÇÃO}

A qualidade microbiológica da água desempenha papel fundamental na determinação da ecologia ambiental, bem como na saúde pública e no desenvolvimento econômico e social. O Brasil é favorecido no que diz respeito à disponibilidade de água doce, todavia, ainda existem muitas dificuldades relacionadas à preservação, abastecimento e saneamento da mesma. Em muitas propriedades situadas no meio rural, não há abrangência pelas redes de distribuição de água, e a captação deste recurso acaba ocorrendo através de nascentes, rios e poços, normalmente sem o devido tratamento e imprópria para o consumo (BORTOLI et al., 2018; XU et al., 2019).

A contaminação fecal de fontes de água é especialmente importante, pois representa uma fonte comum de exposição a microrganismos prejudiciais à saúde que podem se disseminar com extrema velocidade através das águas de rios. Além disso, estudos conduzidos nesta área de conhecimento vêm reforçando a importância de se avaliar as variações sazonais na qualidade de águas superficiais, com a finalidade de analisar mudanças temporais de poluição devido à ação natural ou humana nas fontes de água (OUYANG et al., 2006; TORTORA et al., 2019). Dados dessa natureza são importantes para evitar o uso das águas de rios em intervalos temporais onde a contaminação por coliformes é acentuada. Assim, a transmissão de doenças, tanto para homens como animais, pode ser minimizada.

Ademais, é de amplo conhecimento que atividades domésticas, hospitalares e industriais são fortemente seletivas para microrganismos resistentes, e a liberação de seus efluentes em leitos de curso de água (especialmente rios) transporta os mesmos para diferentes locais, disseminando-os entre humanos e animais. Além disso, contribui para que bactérias pertencentes a microbiotas de ecossistemas naturais atuem como reservatórios de genes de resistência (BAQUERO et al., 2008; MEIRELLES-PEREIRA et al., 2002).

A ocorrência de bactérias multirresistentes em águas de rios é um aspecto preocupante por dois motivos principais: 1) a população do interior usa esse recurso hídrico para fins de consumo humano e animal; 2) o uso para irrigar lavouras e hortas acarreta transferência de microrganismos resistentes da água para o solo, contribuindo para a disseminação de multirresistência em diferentes ambientes (COURVALIN, 2008; SCHNEIDER et al., 2009). Uma vez no solo, as bactérias são transportadas por lixiviação para outros corpos d'água, e assim os microrganismos resistentes a antibióticos passam a ser encontrados nos mais diversos ambientes aquáticos (AL SALAH et al., 2019; URSELER et al., 2019). Nesse sentido, estudos em algumas regiões do Brasil revelam graves problemas em relação à multirresistência em rios e açudes. Na Região Amazônica, por exemplo, Alves et al. (2020) observaram que os percentuais de isolados bacterianos resistentes a antibióticos variaram entre 77 e $99 \%$. Vasconcelos et al. (2010) reportaram que $25,6 \%$ dos isolados de E. coli exibiram resistência à tetraciclina, e 4,7\% à Ciprofloxacina. Percebe-se, na maior parte dos casos, que 
os valores de resistência são relativamente altos em relação ao reportado na literatura e às indicações de agências internacionais de saúde e ambiente, e isso representa um risco muito sério sob o ponto de vista de qualidade ambiental e saúde única. Nesse sentido, o objetivo do presente trabalho foi analisar a qualidade microbiológica de águas de rios localizados no município de Curitibanos, SC, através da avaliação de coliformes fecais, bem como avaliar o perfil de resistência a antibióticos.

\section{MATERIAL E MÉTODOS}

A área de estudo contemplou 5 pontos localizados no município de Curitibanos, SC, inserido na bacia hidrográfica do Rio Canoas, que abrange várias cidades da região do Planalto Catarinense. Os rios avaliados no presente estudo foram o Rio Pessegueirinho e Rio Marombas, localizados em áreas com presença de propriedades rurais, vegetação, residências e indústrias (Figura 1).

Figura 1 - Locais de amostragem de água em Curitibanos - SC.

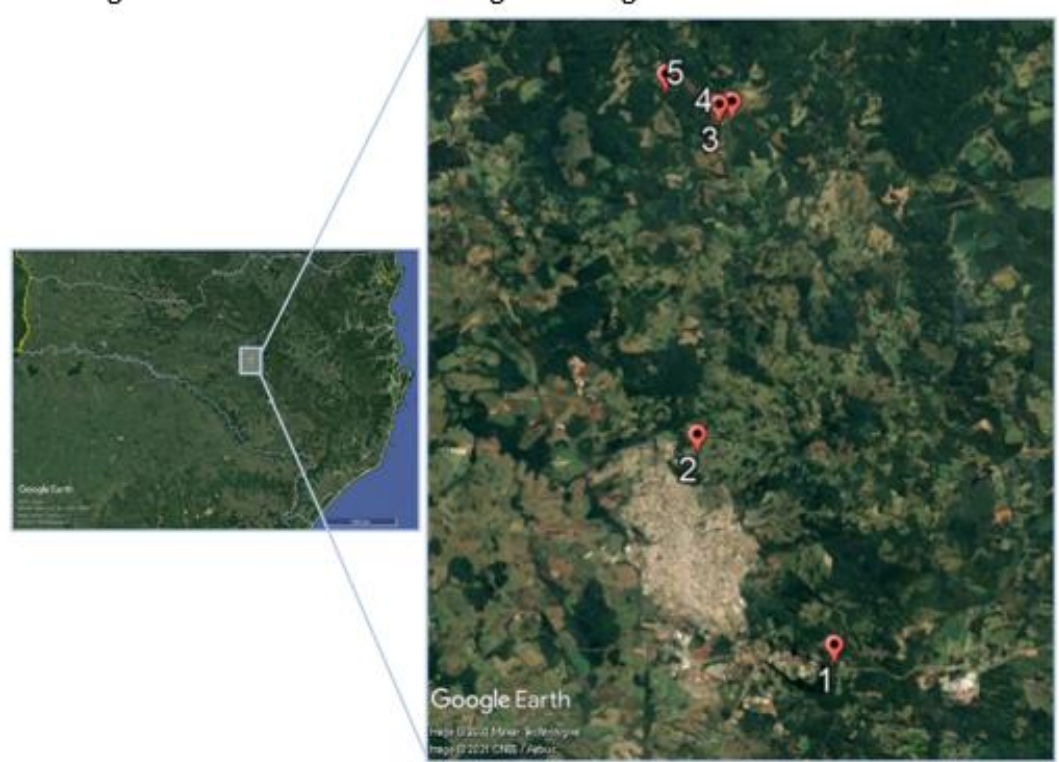

Local correspondente a cada ponto: 1) nascente do Rio Pessegueirinho; 2) Rio Pessegueirinho na localidade da Lagoinha; 3) foz do Rio Pessegueirinho; 4) Rio Marombas próximo ao ponto de captação de água pela Companhia Catarinense de Aguas e Saneamento (CASAN); 5) Rio Marombas após confluência com o Rio Pessegueirinho.

Fonte: Google Earth (2021).

As coletas foram realizadas em duas estações, em que, a primeira parcela ocorreu em outubro de 2020, correspondendo à primavera, e a segunda em fevereiro de 2021, correspondendo ao verão.

Em cada local, foram coletados três frascos de $100 \mathrm{~mL}$ de água dos rios (cada um consistiu em uma repetição amostral). Cada repetição foi avaliada por meio da técnica de tubos múltiplos. A quantificação de coliformes termotolerantes foi feita através do método de N.M.P. - número mais provável (FUNASA, 2013).

Para o teste presuntivo, foram utilizadas séries de 3 tubos com inóculos de 10 $\mathrm{mL}$ em caldo lactosado em concentração dupla, e de $1 \mathrm{~mL}$ e $0,1 \mathrm{~mL}$ em caldo 
lactosado em concentração simples. Estes tubos foram incubados à temperatura de $35^{\circ} \mathrm{C}$, durante um intervalo de 48 horas. Em seguida, procedeu-se à leitura dos resultados, em que o critério para avaliação e determinação de um resultado positivo baseou-se na observação de crescimento bacteriano (turvação do meio), associado à presença de uma bolha de ar no interior dos tubos de Durham, indicando produção de gás.

Dentre os tubos que apresentaram resultado positivo no teste presuntivo, foi realizada a repicagem para tubos contendo caldo E.C., para execução do teste de coliformes termotolerantes. Nesta fase, os tubos foram incubados por um período de 24 horas, à temperatura de $44,5^{\circ} \mathrm{C}$, e em seguida, a leitura dos resultados foi feita seguindo os mesmos critérios utilizados no teste presuntivo. Após a leitura, foi selecionado 1 tubo por repetição que tivesse apresentado resultado positivo na etapa anterior. Estes serviram de inóculo para o isolamento de colônias de E. coli em placas de Petri contendo Ágar MacConkey, realizado através de estriamento simples. Conforme metodologia adotada por Bortoloti et al. (2018), foram selecionadas 4 colônias isoladas de cada placa para realização do teste de suscetibilidade a antimicrobianos por disco-difusão (CLSI, 2002).

Neste estudo foram testadas quatro drogas: Ampicilina $10 \mu \mathrm{g}$. Ampicilina + Sulbactam $10 \mu \mathrm{g} / 10 \mu \mathrm{g}$, Ciprofloxacina $5 \mu \mathrm{g}$ e Tetraciclina $20 \mu \mathrm{g}$. As mesmas e estão divididas nos grupos A, B e C, conforme ordem de escolha que se deve empregar para o tratamento de infecções causadas por enterobactérias (LABORCLIN, 2019).

A Ampicilina é um antimicrobiano beta-lactâmico derivado da penicilina e encontra-se classificada dentro do grupo A. Seu mecanismo de ação possui duas fases, em que, na primeira, o fármaco liga-se a receptores primários na membrana bacteriana. Estes receptores são denominados proteínas de ligação à penicilina, sendo fundamentais para a síntese dos peptidoglicanos da parede celular. Uma vez que estes dois elementos estão ligados, a função da proteína é imediatamente interrompida, dando início à segunda etapa, que consiste na cascata de eventos fisiológicos desencadeados pela união do receptor e ligante (PEECHAKARA; GUPTA, 2020).

Também foi testada neste estudo a associação entre Ampicilina e Sulbactam, sendo a segunda substância um inibidor irreversível de beta-lactamases. As beta-lactamases são enzimas produzidas por bactérias resistentes a esta classe de antimicrobianos, que agem hidrolisando o anel beta-lactâmico da Ampicilina e, consequentemente, impedindo sua ação (PEECHAKARA; GUPTA, 2020).

Para o grupo $\mathrm{B}$, o antibiótico de utilizado foi a Ciprofloxacina, um fármaco bactericida que pertence à classe das fluoroquinolonas, e seu mecanismo de ação consiste na inibição da DNA topoisomerase e DNA girase nas bactérias, 0 que resulta na interrupção da replicação celular (THAI et al., 2021).

$\mathrm{O}$ antibiótico representativo do grupo $\mathrm{C}$ neste caso foi a Tetraciclina, um medicamento que age inibindo de forma específica a subunidade ribossomal bacteriana 30S, impossibilitando a ligação dos aminoácidos do RNA transportador ao seu receptor no complexo ribossomo-RNA mensageiro. Tal evento culmina no impedimento da síntese proteica na célula (SHUTTER; AKHONDI, 2021).

Para realização do teste de suscetibilidade a antimicrobianos, as colônias selecionadas a partir do Ágar MacConkey foram repicadas em tubos de ensaio contendo caldo Muller Hinton, e após, incubadas por 18 horas à temperatura de $35^{\circ} \mathrm{C}$ em uma estufa com agitador. Transcorrido este período, a suspensão bacteriana obtida nos tubos foi semeada em placas com Ágar Muller Hinton, onde também foram posicionados os discos de antibiograma correspondentes a 
cada droga testada. Todos os procedimentos foram efetuados em condições assépticas em câmara de fluxo laminar. Em seguida, estas placas seguiram para incubação à temperatura e intervalo de tempo iguais aos da etapa anterior.

A leitura dos resultados foi realizada através da medição do halo de inibição produzido por cada isolado, em milímetros de diâmetro, com o auxílio de um paquímetro. Os valores obtidos foram registrados em uma planilha para posterior classificação dos isolados em sensível (S), intermediário (I) e resistente (R), com base nos pontos de corte estabelecidos pelo Manual de Antibiograma Laborclin, conforme apresentado na Tabela 1 (LABORCLIN, 2019).

Tabela 1 - Valores de diâmetro de halo inibitório (em milímetros) esperados para Enterobateriaceae e respectivas classificações.

\begin{tabular}{ccccc}
\hline \multirow{2}{*}{ Agente } & \multirow{2}{*}{ Discos } & \multicolumn{3}{c}{ Diâmetro do halo } \\
\cline { 3 - 5 } & & $\mathbf{R}$ & $\mathbf{I}$ & $\mathbf{S}$ \\
\hline Ampicilina & $10 \mu \mathrm{g}$ & $\leq 13$ & $14-16$ & $\geq 17$ \\
Ampicilina + Sulbactam & $10 \mu \mathrm{g} / 10 \mu \mathrm{g}$ & $\leq 11$ & $12-14$ & $\geq 15$ \\
Ciprofloxacina & $5 \mu \mathrm{g}$ & $\leq 21$ & $22-25$ & $\geq 26$ \\
Tetraciclina & $30 \mu \mathrm{g}$ & $\leq 11$ & $12-14$ & $\geq 15$ \\
\hline
\end{tabular}

Fonte: Adaptado de Laborclin (2019).

Como controle de qualidade, foi utilizada a estirpe de Escherichia coli ATCC $\AA$ 25922, recomendada pelo CLSI com o objetivo de garantir acurácia e reprodutibilidade do antibiograma.

\section{RESULTADO E DISCUSSÃO}

A Tabela 2 apresenta os valores médios de concentração de coliformes fecais (NMP $100 \mathrm{~mL}-1$ ) presentes nas amostras de água coletadas do Rio Pessegueirinho e Rio Marombas na primavera de 2020 e verão de 2021.

Tabela 2 - Valores médios de coliformes fecais presentes em amostras de água do Rio Pessegueirinho e Rio Marombas. Dados obtidos em outubro de 2020 e fevereiro de 2021.

\begin{tabular}{ccc}
\hline \multirow{2}{*}{$\begin{array}{c}\text { Pontos de } \\
\text { coleta }^{*}\end{array}$} & \multicolumn{2}{c}{ Média de coliformes fecais (NMP $\mathbf{1 0 0} \mathbf{~ m L}^{-1}$ ) } \\
\cline { 2 - 3 } & $\begin{array}{c}\text { Primavera } \\
\mathbf{2 0 2 0}\end{array}$ & Verão $\mathbf{2 0 2 1}$ \\
\hline $\mathbf{1}$ & 10,86 & 560 \\
$\mathbf{2}$ & 108,33 & 786,66 \\
$\mathbf{3}$ & 39 & 1.100 \\
$\mathbf{4}$ & 15 & 590 \\
$\mathbf{5}$ & 45,33 & 1.100 \\
\hline
\end{tabular}

*Local correspondente a cada ponto: 1) nascente do Rio Pessegueirinho; 2) Rio Pessegueirinho na localidade da Lagoinha; 3) foz do Rio Pessegueirinho; 4) Rio Marombas próximo ao ponto de captação de água pela Companhia Catarinense de Aguas e Saneamento (CASAN); 5) Rio Marombas após confluência com o Rio Pessegueirinho.

Fonte: Elaborada pelos autores (2021).

Com relação às amostras coletadas na primavera de 2020 , as contagens de coliformes totais e fecais variaram de 3 até $1.100 \mathrm{NMP} 100 \mathrm{~mL}-1$. No verão de 2021, as amostras apresentaram variação no número de coliformes entre 120 a $>1.100$ NMP $100 \mathrm{~mL}-1$. 
$\mathrm{Na}$ Tabela 3 encontram-se agrupados os percentuais de resistência de isolados de coliformes fecais das amostras de água, frente aos quatro antimicrobianos testados. Na primavera, 3,33\% dos isolados foram suscetíveis a apenas 1 antibiótico. Não houve resistência a 2 ou mais antibióticos, simultaneamente. Dados da coleta realizada no verão, revelaram que $3,33 \%$ dos isolados apresentou resistência a 3 drogas, simultaneamente. 8,33\% foram resistentes a 2 antibióticos, enquanto $36,66 \%$, a apenas um.

Tabela 3 - Percentuais de resistência a antibióticos em coliformes fecais isolados de amostras de água do Rio Pessegueirinho e Rio Marombas. Dados obtidos em outubro de 2020 e fevereiro de 2021.

\begin{tabular}{ccc}
\hline Antibiótico & Primavera 2020 & Verão 2021 \\
\hline AMP & $1,66 \%$ & $21,66 \%$ \\
SBA & $0 \%$ & $5 \%$ \\
CIP & $0 \%$ & $1,66 \%$ \\
TET & $1,66 \%$ & $35 \%$ \\
\hline \multicolumn{2}{r}{ Fonte: Elaborada pelos autores (2020). }
\end{tabular}

As informações levantadas no presente estudo confirmam, particularmente, que a contaminação com altos valores de coliformes fecais é frequente no Rio Pessegueirinho. Em estudo previamente conduzido no mesmo rio, Campos et al. (2017) avaliaram a qualidade da água em três pontos. Em um deles observou-se valor de coliformes termotolerantes igual a 2,3×103 UFC $100 \mathrm{~mL}$ 1, outro no ponto de confluência, apresentando 4,7×103 UFC $100 \mathrm{~mL}-1$, enquanto em outro ponto o valor foi de 8,9×103 UFC $100 \mathrm{~mL}-1$. Esses resultados são semelhantes ao do presente estudo, uma vez que, a quantidade de coliformes fecais foi crescente nos pontos adiante da nascente. Além disso, os autores afirmaram que a qualidade da água do rio em questão é afetada pela liberação de efluentes industriais no corpo hídrico e que a área rural do município deve ser monitorada no que diz respeito ao esgotamento sanitário, ao passo que a concentração de coliformes termotolerantes encontrava-se acima do permitido na legislação pertinente para águas de Classe II (CONAMA, 2005).

O uso da água de rios, principalmente pela população de regiões do interior, normalmente é feito sem qualquer análise química ou microbiológica. Esse é um fator preocupante, uma vez que o Governo Federal Brasileiro determina, através da Resolução CONAMA 357/2005, níveis toleráveis de poluentes de acordo com a finalidade de uso da água. A mesma estabelece classes de acordo com parâmetros químicos, físicos e microbiológicos (especial, 1, 2, 3 e 4, estabelecidas de acordo com níveis crescentes de poluentes) e determina os usos possíveis para cada uma delas. Para irrigação de hortaliças, por exemplo, - limite é de 200 coliformes fecais a cada 100mL (classe 1). Já para dessedentação animal, esse valor é de 1.000 (classe 2), enquanto para irrigação de culturas arbóreas e cerealíferas o limite é de 2.500 coliformes fecais a cada $100 \mathrm{~mL}$ de água, o que corresponde a classe 3 (CONAMA, 2005). Portanto, trabalhos de monitoramento de coliformes em rios são essenciais para que a população seja orientada e faça o uso correto e racional dos recursos hídricos. Estudos dessa natureza são também registrados em outros países, e recebem crescente atenção de pesquisadores. Como exemplo, alta contaminação por coliformes fecais em águas a jusante da nascente foi também observada por Tripathi e Sharma (2011), pois ao perpassar pelo perímetro da cidade, o rio 
recebe todo seu esgoto. Os autores, ao avaliarem variações sazonais na ocorrência de coliformes fecais em águas superficiais e subterrâneas e seu perfil de resistência a antibióticos, verificaram níveis mais altos de contaminação durante o verão. Além disso, $100 \%$ dos isolados de coliformes fecais deste estudo demonstraram resistência à ampicilina e $83,33 \%$ à tetraciclina. A ocorrência de resistência à ampicilina também foi observada por Diwan et al. (2018) no Rio Kshipra, situado na Índia, correspondendo a 33\% dos isolados na estação chuvosa. No entanto, neste estudo o verão demonstrou ser o período com os menores percentuais de resistência, com $17 \%$ dos isolados manifestando resistência à ampicilina, diferindo dos resultados do presente trabalho. Em Curitibanos, o período que antecedeu a coleta do verão foi marcado por um regime de chuvas concentradas, o que pode ter colaborado para lixiviação de bactérias do solo para as águas dos rios, contribuindo assim com maiores porcentagens de ocorrência de resistência.

De fato, a disseminação de bactérias resistentes a antibióticos pode estar relacionada a atividades do entorno dos corpos d'água, sejam elas de natureza agrícola, industrial ou até mesmo doméstica, como já reportado em vários registros literários. A identificação dessas fontes pontuais de poluição é, portanto, essencial para diminuir o aporte de contaminantes microbianos nos rios e poços.

O presente trabalho traz foco para rios como sendo potenciais reservatórios e contribuintes para dispersão de resistência antimicrobiana, o que é um aspecto preocupante do ponto de vista ambiental. Nas últimas décadas, acreditava-se que a ocorrência de bactérias resistentes a antibióticos era restrita a ambientes hospitalares, onde a frequência desses microrganismos é naturalmente esperada devido ao uso recorrente de antibióticos. Porém, com o avanço dos trabalhos nessa linha de pesquisa, evidenciou-se não somente sua ocorrência, mas também disseminação no solo e na água (seja de rios, poços ou até mesmo ambientes marinhos). No caso de ambientes aquáticos, a principal fonte de microrganismos resistentes a antibióticos são fezes, sejam elas oriundas de esgoto não tratado ou de animais de criação que defecam nas proximidades dos corpos d'água (MASSE et al., 2010; SINGH et al., 2021).

A ingestão de água que apresente bactérias resistentes seguramente contribui para agravar a incidência de infecções fatais, seja em populações humanas ou animais. Esse fato certamente representa um problema de saúde única, que deve ser combatido por todos os setores da sociedade, contribuindo para a qualidade de vida das gerações atuais e futuras.

\section{CONSIDERAÇÕES FINAIS}

Os resultados revelaram que as amostras apresentavam grande carga de contaminação por bactérias resistentes na água dos rios abrangidos neste estudo, principalmente no verão, quando as pessoas tendem a utilizar os corpos d'água com fins recreativos, indicando alto risco para a saúde dos indivíduos que os utilizam. É notável a importância de se realizar mais estudos que monitorem aspectos da qualidade microbiológica da água nesses locais, e também de orientar a população das comunidades rurais para o tratamento adequado dos recursos hídricos.

\section{REFERÊNCIAS}


AMERICAN DIABETES ASSOCIATION. Standards of medical care in diabetes2018. Diabetes Care, v. 33, p. 11-61, 2010.

AL SALAH, Dhafer Mohammed M.; LAFFITE, Amandine; POTÉ, John. Occurrence of bacterial markers and antibiotic resistance genes in sub-saharan rivers receiving animal farm wastewaters. Scientific Reports, [s.I.], v. 9, n. 14847, p. 1-10, 2019. Disponível em: <https://www.nature.com/articles/s41598-01951421-4>. Acesso em: 10 ago. 2021.

ALVES, Jorianne. et al. Resistome in Lake Bolonha, Brazilian Amazon: Identification of genes related to resistance to broad-spectrum antibiotics. Frontiers in Microbiology, [s.I.], v. 11, n. 67, p. 1-11, 2020. Disponível em: $<$ https://www.frontiersin.org/articles/10.3389/fmicb.2020.00067/full>. Acesso em 10 ago. 2021.

BAQUERO, Fernando.; MARTÍNEZ, José-Luis.; CANTÓN, Rafael. Antibiotics and antibiotic resistance in water environments. Current Opinion in Biotechnology, [s.I.], v. 19, n. 3, p. 260-265, jun. 2008. Disponível em: <https://pubmed.ncbi.nlm.nih.gov/18534838/>. Acesso em: 08 ago. 2021.

BORTOLI, Jaqueline de. et al. Avaliação microbiológica da água em propriedades rurais produtoras de leite localizadas no Rio Grande do Sul, Brasil. Revista Brasileira de Higiene e Sanidade Animal, [s.I.], v. 12, n. 1, p. 39-53, 2018. Disponível em: <http://www.higieneanimal.ufc.br/seer/index.php/higieneanimal/article/view/426 >. Acesso em: 08 ago. 2021.

BORTOLOTI, Karina da Costa Sassi. et al. Qualidade microbiológica de águas naturais quanto ao perfil de resistência de bactérias heterotróficas a antimicrobianos. Engenharia Sanitaria e Ambiental, [s.I.], v. 23, n. 4, p. 717-725, 28 jun. 2018. Disponível em: <https://www.scielo.br/j/esa/a/z85TnHCTYRHJD6pKDNNkj8H/>. Acesso em: 14 ago. 2021.

CAMPOS, Roger Ferreira Francisco de; BORGA, Tiago; VAZQUEZ, Eric Marcos. Análisis de la interacción de un efluente industrial con el Índice de Calidad del Agua del Río Pessegueirinho, Curitibanos, Santa Catarina, Brasil. Revista Eletrônica em Gestão, Educação e Tecnologia Ambiental, Santa Maria, v. 21, n. 2, p. 179-185, 2017. Disponível em: <https://periodicos.ufsm.br/reget/article/view/28220>. Acesso em: 08 ago. 2021.

CLINICAL AND LABORATORY STANDARDS INSTITUTE. M2-A8: Padronização dos Testes de Sensibilidade a Antimicrobianos por Disco-difusão. 8 ed. Wayne, PA, USA: Anvisa, 2002. v. 23. Disponível em: $<$ https://www.anvisa.gov.br/servicosaude/manuais/clsi/clsi_OPASM2-A8.pdf>. Acesso em: 08 ago. 2021.

CONSELHO NACIONAL DO MEIO AMBIENTE. Resolução CONAMA N 357, de 17 de março de 2005. Disponível em: $<$ http://www2.mma.gov.br/port/conama/legiabre.cfm?codlegi=459>. Acesso em: 08 ago. 2021. 
COURVALIN, P. Predictable and unpredictable evolution of antibiotic resistance. Journal of Internal Medicine, [s.I.], v. 264, n. 1, p. 4-16, 2008. Disponível em: <https://pubmed.ncbi.nlm.nih.gov/18397243/>. Acesso em: 10 ago. 2021.

DIWAN, Vishal. et al. Seasonal Variations in Water-Quality, Antibiotic Residues, Resistant Bacteria and Antibiotic Resistance Genes of Escherichia coli Isolates from Water and Sediments of the Kshipra River in Central India. International Journal of Environmental Research and Public Health, [s.I.], v. 15, n. 6, p. 1281, 17 jun. $2018 . \quad$ Disponível em: <https://www.ncbi.nlm.nih.gov/pmc/articles/PMC6024939/>. Acesso em: 10 ago. 2021.

FUNDAÇÃO NACIONAL DA SAÚDE. Manual Prático de Análise de Água. 4. ed. Brasília: Fundação Nacional de Saúde, 2013. 144 p. Disponível em: $<$ http://www.funasa.gov.br/site/wp-

content/files_mf/manual_pratico_de_analise_de_agua_2.pdf >. Acesso em: 08 ago. 2021.

GOOGLE. Digital Globe; CNES. Google Hearth, 2021.

LABORCLIN. Manual de Antibiograma. Pinhais: Laborclin Produtos Para Laboratórios Ltda., 2019. $54 \quad$ p. Disponível em: $<\mathrm{https}: / /$ www.laborclin.com.br/wpcontent/uploads/2019/05/Manual_antibiograma_2019.pdf>. Acesso em: 08 ago. 2021.

MASSE, Lucie. et al. Microbial and physico-chemical characteristics of surface water sources used on dairy farms in Ontario. Water Quality Research Journal of Canada, [s.I.], v. 45, n. 3, p. 287-294, 2010. Disponível em: $<$ https://iwaponline.com/wqrj/article/45/3/287/39723/Microbial-and-PhysicoChemical-Characteristics-of>. Acesso em: 10 ago. 2021.

MEIRELLES-PEREIRA, Frederico de. et al. Ecological aspects of the antimicrobial resistence in bacteria of importance to human infections. Brazilian Journal of Microbiology, São Paulo, v. 33, n. 4, p. 287-293, dez. 2002. Disponível em: <https://www.scielo.br/j/bjm/a/FM8LCBHPtS7mRzP6gDhGbWL/>. Acesso em: 08 ago. 2021

OUYANG, Y. et al. Assessment of seasonal variations in surface water quality. Water Research, [s.I.], v. 40, n. 20, p. 3800-3810, dez. 2006. Disponível em: <https://pubmed.ncbi.nlm.nih.gov/17069873/>. Acesso em: 08 ago. 2021.

PEECHAKARA, Basil B.; GUPTA, Mohit. Ampicillin/Sulbactam. In: StatPearls [Internet]. $2020 . \quad$ Disponível em: <https://www.ncbi.nlm.nih.gov/books/NBK526117/>. Acesso em: 14 ago. 2021.

SCHNEIDER, Roger Neto.; NADVORNY, André; SCHMIDT, Verônica. Perfil de resistência antimicrobiana de isolados de Escherichia coli obtidos de águas superficiais e subterrâneas, em área de produção de suínos. Biotemas, [s.l.], v. 22, n. 3, p. 11-17, 2009. Disponível em: <https://www.researchgate.net/publication/273609633_Perfil_de_resistencia_a ntimicrobiana_de_isolados_de_Escherichia_coli_obtidos_de_agua_superficiais 
_e_subterraneas_em_area_de_producao_de_suinos>. Acesso em: 10 ago. 2021.

SHUTTER, Mollie C.; AKHONDI, Hossein. Tetracycline. In: StatPearls [Internet]. 2021. Disponível em: <https://www.ncbi.nlm.nih.gov/books/NBK549905/>. Acesso em: 14 ago. 2021.

SINGH, Ajay Kumar; BHARDWAJ, Satish Kumar; DEVI, Sunita. Microbiological status of drinking water sources and its relationship with human health in Solan, India. Environmental Monitoring and Assessment, [s.I.], v. 193, n. 32, 2021. Disponível em: <https://pubmed.ncbi.nlm.nih.gov/33403463/>. Acesso em: 10 ago. 2021.

THAI, Tony; SALISBURY, Blake H.; ZITO, Patrick M. Ciprofloxacin. In: StatPearls [Internet]. 2021. Disponível em: <https://www.ncbi.nlm.nih.gov/books/NBK535454/>. Acesso em: 14 ago. 2021.

TRIPATHI, Kshama; SHARMA, A. K. Seasonal variation in bacterial contamination of water sources with antibiotic resistant faecal coliforms in relation to pollution. Journal of Applied and Natural Science, [s.I.], v. 3, n. 2, 298302, $2011 . \quad$ Disponível em: $<$ https://journals.ansfoundation.org/index.php/jans/article/view/202>. Acesso em: 08 ago. 2021.

TORTORA, Gerard J. et al. Microbiology: an introduction. 13. ed. Boston: Pearson, 2019.

URSELER, Noelia Luján. et al. Calidad microbiológica Y usos del agua subterránea en establecimientos agropecuarios del Centro-Sur de Córdoba, Argentina. Revista Internacional De Contaminación Ambiental, [s.I.], v. 35, n. 4, p. 2019. 839-848, Disponível em: <https://www.revistascca.unam.mx/rica/index.php/rica/article/view/RICA.2019.3 5.04.06 >. Acesso em: 10 ago. 2021.

VASCONCELOS, Fábio R. et al. Perfil de resistência antimicrobiana de Escherichia coli isoladas do açude Santo Anastácio, Ceará, Brasil. Arquivos do Instituto Biológico, [s.I.], v. 77, n. 3, p. 405-410, 2010. Disponível em: <https://www.scielo.br/j/aib/a/qhbfz6cxbtGDSJBZn5pDhXM>. Acesso em: 10 ago. 2021.

$\mathrm{XU}$, Guoce. et al. Seasonal changes in water quality and its main influencing factors in the Dan River basin. Catena, [s.I.], v. 173, p. 131-140, fev. 2019. Disponível em: $<$ https://agris.fao.org/agrissearch/search.do?recordID=US201900011301>. Acesso em: 08 ago. 2021.

Recebido em: 20-08-2021

Aceito em: 28-09-2021 